\title{
Registro eletrônico de saúde em hospital de alta complexidade: um relato sobre o processo de implementação na perspectiva da telessaúde
}

\author{
Electronic health records in high complexity hospitals: a report \\ on the implementation process from the telehealth perspective
}

Angélica Baptista Silva ${ }^{1}$

Ana Cristina Carneiro Menezes Guedes ${ }^{2}$

Sérgio Ricardo Ferreira Síndico ${ }^{3}$

Eliane Tarlen Ruas Castro Vieira ${ }^{1}$

Ianê Germano de Andrade Filha ${ }^{4}$

${ }^{1}$ Laboratório de Telessaúde, Instituto Nacional de Saúde da Mulher, da Criança e do Adolescente Fernandes Figueira, Fiocruz. Av. Rui Barbosa 716, Flamengo. 22.250-020 Rio de Janeiro RJ Brasil. silva.angelica@ gmail.com

${ }^{2}$ Departamento de Ensino, Hospital Federal dos Servidores do Estado, Ministério da Saúde. Rio de Janeiro RJ Brasil.

${ }^{3}$ Biblioteca do IFF, Instituto de Comunicação e Informação Científica e Tecnologia em Saúde, Fiocruz. Rio de Janeiro RJ Brasil.

${ }^{4}$ Instituto de Estudos em Saúde Coletiva, Universidade Federal do Rio de Janeiro. Rio de Janeiro RJ Brasil.

\begin{abstract}
The implementation of electronic records in healthcare establishments has led to isolated solutions, which contribute to the fragmentation of the Brazilian Unified Health System (SUS). This research uses a strategic planning tool in order to monitor the trajectory of implementation of the records in medium and high complexity hospitals, which are a benchmark for the health of women and children. The scope was to outline possible contributions for the computerization of health facilities in general. The methodology is based on the ethnography practices in hospitals. The study was qualitative, descriptive with document analysis. The sources consulted were the minutes of the electronic records kept between 2012 and 2015. The synthetic narrative points to the lack of infrastructure, resources and the conflict of interests involving several actors in the process. The electronic record legitimizes the institutional design and organizes the work, besides mapping the hospital geography. The association of physical and digital records demands a change of institutional culture. Registration is an act of citizenship and becomes a key document in quality control and hospital accreditation.
\end{abstract}

Key words Child health services, Telehealth, Communication in health, Women's health services
Resumo A implantação do registro eletrônico nos estabelecimentos de saúde tem refletido soluções isoladas, que contribuem para a fragmentação do Sistema Único de Saúde (SUS). Essa investigação utiliza ferramenta de planejamento estratégico, a fim de acompanhar o percurso da implantação do registro em instituto nacional de média e alta complexidade, referência na área da saúde da mulher e da criança. O objetivo foi delinear possíveis contribuições para a informatização de estabelecimentos de saúde em geral. A metodologia se baseia nas práticas da etnografia nos hospitais. $O$ desenho do estudo foi qualitativo, descritivo com análise documental. As fontes consultadas foram as atas dos encontros para implementação do prontuário eletrônico realizados entre $2012 \mathrm{e}$ 2015. Uma narrativa sintese aponta a falta de infraestrutura, de recursos e a ocorrência de conflito de interesses, envolvendo vários atores no processo. O registro eletrônico legitima o desenho institucional e organiza o trabalho, além de mapear a geografia hospitalar. A associação do prontuário físico com o digital exige uma mudança de cultura institucional. O registro é um ato de cidadania e se torna um documento fundamental no controle de qualidade e na acreditação hospitalar.

Palavras-chave Serviços de saúde da criança, Telessaúde, Comunicação em saúde, Serviços de saúde da mulher 


\section{Introdução}

Implantada no Brasil nos anos 2000, a Telessaúde foi concebida com o propósito de apoiar a reorganização dos serviços e contribuir para ampliação do acesso aos cuidados em saúde, favorecendo a consolidação do princípio doutrinário de universalização do Sistema Único de Saúde, (SUS).

A potencialidade da Telessaúde foi ampliada com o advento da internet das coisas e a ubiquidade computacional. Ambas, em resumo, significam que a computação está presente, e ao mesmo tempo invisível, em todos os momentos da vida humana, na atualidade. Vários dispositivos, como vestuário "inteligente" e smartphones, estão facilitando o diagnóstico da clínica e contribuindo para a qualidade de vida de indivíduos em diferentes fases da vida. No âmbito da saúde pública, têm contribuído para avanços da genômica populacional, na tomada de decisão para o planejamento e a regulação da rede de serviços do cuidado ${ }^{1}$.

O Brasil acompanha a tendência mundial de informatização do sistema de saúde e, desde os anos 80 , tem procurado soluções para criar um cadastro único de saúde dos cidadãos. Esse cadastro, que também gerou o Cartão Nacional de Saúde, envolve questões diversas, como unir dados dos usuários dos planos de saúde privados que usam o sistema público, bem como desenvolver uma base de dados que congregue todo o histórico de saúde. Essa ambição é ainda maior quando o intuito de unir os sistemas de informação em saúde com o Cadastro Nacional de Saúde se configura em desafio para lidar com a fragmentação de sistemas concebidos com fins e em épocas distintas, parte do contexto de implantação do registro eletrônico de saúde ${ }^{2}$.

É possível inferir que a estrutura física e informatização necessárias e utilizadas para implementação da Telessaúde são consideradas aliadas ao desenvolvimento do registro eletrônico em saúde numa concepção sistêmica.

Na década de 90, o Programa Saúde da Família interiorizou profissionais de saúde em regiões remotas. A partir de 2006, investiu-se na comunicação e na educação permanente à distância desses profissionais, com o estabelecimento do Programa Telessaúde Brasil Redes ${ }^{3}$.

Apesar desse avanço na atenção básica do SUS, o Brasil ainda conta com um modelo de serviço hospitalocêntrico ${ }^{4}$, em que inovações em tecnologia da informação e comunicação (TIC) vêm prosperando, primeiro, em hospitais de alta complexidade de ensino e pesquisa ${ }^{5}$.
Ações de planejamento e de gestão incrementadas pela TIC têm sido amplamente utilizadas nos hospitais para, inclusive, prospecção estratégica e estabelecimento de política institucional. Com vistas à melhoria da qualidade do atendimento, os hospitais vêm se submetendo a certificações e acreditações, exigindo também o upgrade tecnológico que reduz erros e apoia a segurança do paciente ${ }^{6}$.

O Registro Eletrônico de Saúde (RES), no Brasil, também é muito conhecido como Prontuário Médico Eletrônico (PME) ou Prontuário Eletrônico do Paciente (PEP). Na literatura internacional, as designações mais utilizadas são Eletronic Medical Record (EMR) e Eletronic Health Record (EHR). A distinção entre os dois termos referese, principalmente, à sua utilização institucional. A sigla EMR é utilizada quando as informações armazenadas referirem-se a um serviço ou a um provedor individual como em um consultório ou hospital. Já quando estiverem relacionados por meio de múltiplos provedores são chamados EHR. Nesta pesquisa, optou-se por não realizar essa distinção e designar ambos como RES ${ }^{2,7,8}$.

Telessaúde tem sido definida como modalidade de saúde à distância pela OMS. No entanto, na literatura há uma série de significações para o termo. Adota-se para fins desta análise o conceito de que telessaúde é toda atividade em rede, mediada por computação, que promove o intercâmbio de conhecimento entre a pesquisa e a atenção à saúde ${ }^{9}$. Nesse sentido, a pesquisa direcionada ao aprimoramento do registro eletrônico de saúde se configura como um tópico de telessaúde no planejamento de serviços de saúde.

Observa-se como problema a ser equacionado que a implantação do RES em estabelecimentos de saúde tem refletido soluções isoladas, fragmentadas ${ }^{10}$, que ameaçam a regulação do SUS e as conexões necessárias entre os três níveis de atenção ${ }^{11}$, a fim de garantir o atendimento integral e de qualidade ao cidadão usuário do sistema de saúde ${ }^{12-15}$.

Nessa pesquisa, utilizou-se a ferramenta de planejamento estratégico SWOT, acrônimo de strengths, weaknesses, opportunities and threats, forças, fraquezas, oportunidades e ameaças ${ }^{16}$ para investigar o percurso da implantação do registro eletrônico de saúde no Instituto Nacional de Saúde da Mulher, da Criança e do Adolescente Fernandes Figueira da Fundação Oswaldo Cruz (IFF/Fiocruz), hospital referência em atendimento de alta complexidade para as referidas populações, com atividades multicêntricas de ensino e pesquisa. 
O referencial teórico utilizado, a priori, nessa observação da implantação do RES é o apresentado por Berg e Bowker, trabalhando a questão da etnografia nos hospitais ${ }^{10}$. Segundo os autores, o RES registra a trajetória da doença no corpo do indivíduo, a organização do trabalho feito ao longo do período do tratamento da patologia e o impacto em todos os envolvidos. Eles argumentam que essa trajetória da doença é sempre registrada em função de uma série de arranjos organizacionais $^{10}$.

Para sumarizar esses arranjos de forma sistemática, realizamos estudo qualitativo com análise documental, que, segundo Bardin ${ }^{17}$, é um conjunto de operações para representar o conteúdo de um documento em uma forma diferente do original, com a representação condensada da informação. Já a análise posterior de conteúdo ocorreu em três fases: pré-análise; exploração do material e tratamento dos resultados com inferência e interpretação.

As atas dos encontros periódicos para implantação do sistema de registro eletrônico de saúde no hospital, no período de outubro de 2012 a outubro de 2015, foram a fonte primária da pesquisa. Participaram regularmente dos encontros: a equipe de informática, servidores designados como gestores pela direção do hospital, gerentes da empresa contratada (proprietária do produto adquirido) e, esporadicamente, representantes dos setores em que o sistema estava sendo implantado.

Durante a fase de pré-análise, 62 documentos foram condensados em um arquivo. Foi elaborado roteiro para a análise sequencial, visando não apenas recuperar cronologicamente a experiência, como também efetuar a análise categorial de conteúdo por reagrupamento analógico, conforme prevê o método. Ao mesmo tempo, efetuouse revisão de literatura direcionada ao estado da arte na implantação do registro eletrônico de saúde no Brasil e no mundo com o auxílio da análise SWOT (Quadro 1).

A estratégia de busca foi centrada no levantamento de estudos acerca da implantação de registros eletrônicos de saúde no mundo. Em virtude da temática desta pesquisa baseada no campo da saúde, optamos por utilizar como descritor de

assunto o termo "Eletronic Health Records", retirado do vocabulário controlado da Biblioteca Nacional de Medicina dos Estados Unidos, $\mathrm{Me}$ dical Subject Headings (MESH). O outro termo pesquisado, a Matriz SWOT, não é um descritor do MESH; portanto, foi utilizado, relacionado ao primeiro termo, como palavra livre ou linguagem natural.

No que tange às fontes de informação utilizadas para este levantamento, executamos as buscas em bases especializadas na literatura em ciências da saúde, com cobertura internacional, no PubMed, Cochrane Library e EBSCO, e na base multidisciplinar SCOPUS. Buscamos ainda em bases especializadas na área de ciências da computação, em decorrência da temática de registros eletrônicos, IEEE Xplore, Computer and Applied Sciences Complete, ACM Digital Library, Computer and Information Systems, e no Repositório Científico de Acesso Aberto de Portugal.

As categorias selecionadas para a análise do material foram as previstas na matriz SWOT para planejar atividades, sendo essas as forças e fraquezas (na dimensão institucional/interna), oportunidades e ameaças (dimensão ambiental/ externa).

O material foi analisado por quatro pesquisadores, que receberam o roteiro. Um deles é membro técnico do time de implantação do RES no hospital terciário e acompanha as reuniões citadas.

Dois pesquisadores receberam a análise dos quatro pesquisadores e fizeram a síntese das categorias. Essa síntese foi validada por todo o grupo em uma série de reuniões presenciais de consenso, cujas discussões ocorreram à luz da literatura recuperada. Quanto aos aspectos éticos, a pesquisa foi aprovada pelo Comitê de Ética em Pesquisa do IFF.

\section{Resultados}

\section{Histórico do projeto RES na visão dos pesquisadores}

O Instituto, com mais de 90 anos de existência, está sediado em prédios antigos, nos quais as construções não tinham como prever carga elétrica, dutos suficientes e separados para passagem de cabeamento elétrico necessário, de rede de computadores e aterramento confiáveis para as demandas tecnológicas atuais. A implantação foi em uma instituição pública, onde há carência de recursos materiais e humanos de diversas ordens. 
Quadro 1. Sumário das categorias pela análise SWOT,

\begin{tabular}{|c|c|}
\hline \multicolumn{2}{|c|}{ Ambiente Interno } \\
\hline $\begin{array}{l}\text { Forças } \\
\text { Planejamento prévio. } \\
\text {. Resposta da comunidade profissional do Instituto. } \\
\text {. Integração de procedimentos. } \\
\text {. Possibilidade de repensar a prática de trabalho. } \\
\text {. Infraestrutura de rede renovada. } \\
\text {. Vantagens do sistema adquirido. }\end{array}$ & $\begin{array}{l}\text { Fraquezas } \\
\text {. Divergências internas. } \\
\text {. Infraestrutura interna insuficiente. } \\
\text {. Falta de adesão de setores estratégicos da organização. } \\
\text {. Limitações do sistema adquirido. } \\
\text {. Suporte deficiente da empresa contratada. }\end{array}$ \\
\hline \multicolumn{2}{|c|}{ Ambiente Externo } \\
\hline $\begin{array}{l}\text { Oportunidades } \\
\text {. Possibilidade de implantação de práticas que } \\
\text { venham a gerar padronização das informações. } \\
\text {. Participar de fóruns de regulação das comissões } \\
\text { bi e tripartite do SUS no que diz respeito à } \\
\text { informatização. } \\
\text {. Comparar outros sistemas que estão sendo } \\
\text { implantados em hospitais de alta complexidade da } \\
\text { administração pública. } \\
\text {. Estabelecer acordo para utilizar infraestrutura } \\
\text { computacional interna do centro de processamento } \\
\text { de dados da instituição. }\end{array}$ & $\begin{array}{l}\text { Ameaças } \\
\text {. Reestruturação organizacional por dificuldades } \\
\text { financeiras da matriz da empresa contratada em outro } \\
\text { país. } \\
\text {. Cortes de orçamento e subfinancimento devido à crise } \\
\text { econômica e política do Brasil. } \\
\text {. Dificuldades de interoperabilidade com outros } \\
\text { sistemas de registro eletrônico de saúde, que estão } \\
\text { sendo implantados no SUS, em especial, o E-SUS AB e } \\
\text { Hospitalar. } \\
\text {. Sistemas isolados em setores que dificultem a vigilância } \\
\text { interna, a pesquisa e o controle da segurança do paciente } \\
\text { por parte do corpo clínico. }\end{array}$ \\
\hline
\end{tabular}

Fonte: Os autores.

As reuniões do grupo de trabalho - designado pela direção para a implantação do sistema de prontuários eletrônicos com vistas ao armazenamento e circulação das informações registradas durante o atendimento dos pacientes - consistiram na discussão das ações destinadas ao cadastro e circulação de informações no sistema (adequar os processos de trabalho à ferramenta adquirida); no uso (erros de saída de relatórios, interface e treinamento, acesso/segurança e hierarquia de senhas); bem como na automação do processo (substituição de formulários em papel) e infraestrutura (aquisição de equipamentos, convergência de sistemas e equipamentos, funcionamento da rede).

Em 2012, embora tenha se discutido bastante sobre o sistema de prontuário eletrônico da empresa contratada, a instituição sofria com muitos problemas de infraestrutura ainda não solucionados. A rede de alta velocidade a ser instalada não estava operante no local, equipamentos estavam em fase de licitação e o sistema RES não tinha a certificação exigida pelo Conselho Federal de Medicina (CFM). A estratégia inicial foi mapear o que era necessário, para que o sistema RES fosse implantado e para isso algumas pendências foram levantadas e abordadas no decorrer das reuniões. Módulos do centro cirúrgico e de almoxarifado já estavam prontos e discutiamse treinamentos. À época, a implantação do sistema já prescindia de infraestrutura de redes de computadores, internet, maquinário e no-breaks/geradores, visando garantir fornecimento de energia elétrica com características e padrões mínimos colocados pelos fornecedores do software.

Em abril de 2013, o link de rede de alta velocidade começou a funcionar com flutuações e ausências que se repetiram ao longo do ano. Houve dúvida na instalação de módulos administrativos, (cirurgia, internação) que atenderiam partes do hospital por demanda da direção. Porém, o sistema, segundo a empresa contratada, geralmente, é instalado a partir do paper free hospital (PFH). Cabe observar que alguns setores/pessoas resistiram à implantação, tendo sido constatadas dificuldades quanto a algumas capacitações, pois a coordenação do projeto começou a apontar deslocamento de pessoal para realizar as tarefas previstas pelos módulos administrativos. A previsão era que a máquina servidora do sistema ficasse aos cuidados da equipe central de informática da instituição e não sob responsabilidade local.

O módulo de dose unitária da farmácia necessário para o setor foi motivo de muito debate, pois não estava previsto no sistema adquirido. 
Isso implicou a oneração do contrato, pois havia necessidade de desenvolvimento adicional, segundo a empresa. De acordo com a infraestrutura do hospital, ficou estabelecido que os ambulatórios da pediatria e da ginecologia seriam os primeiros a serem beneficiados com o PFH. Com os testes, verificou-se demora na resposta do sistema, atribuída à velocidade de rede. A instabilidade da rede e a falta de um link de contingência paralisou a implantação do $P F H$ nos ambulatórios em agosto.

Constatou-se a necessidade de criar um serviço de admissão e alta hospitalar para registro das internações no sistema. Houve dificuldades porque o serviço requeria contratação de profissionais.

Uma política de substituição do papel foi discutida com as chefias de serviços e ambulatórios ao longo do segundo semestre. Enquanto isso, o sistema foi implantado em setores com uso de imagem (radiologia, anatomia patológica e citopatologia). Buscou-se integração do RES com esses sistemas de diagnóstico. Devido ao custo para desenvolvimento das interfaces, foi priorizada a execução da interface com o sistema de imagem PACS-WEB e o laboratorial, X-CLINIC, utilizados por todas as clínicas. Interfaces com outros sistemas usados pela assistência foram tópico constante da pauta de reuniões.

Na discussão sobre a implantação do módulo de agendamento eletrônico, os setores preferiram gerir suas agendas separadamente, em detrimento de uma central de agendas. Dificuldade recorrente foi o registro do agendamento de atendimento multidisciplinar, pois o sistema atribui um registro a um único indivíduo e não poderia ser meio de aferição de produção.

Foi desenvolvido um sistema web para autocadastro dos profissionais. À medida que cada módulo foi sendo implantado nos serviços, a chefia responsável encaminhou relação da força de trabalho para vinculações e habilitações no uso do novo módulo. A força de trabalho engloba servidores, profissionais terceirizados, residentes e pesquisadores.

Ao longo desse processo, houve sugestões quanto ao fluxo de atualização cadastral e com base na ficha de cadastro de outro instituto, foi criado formulário para cadastro de novos profissionais. Foi informado que nem todos os setores estavam efetivando as consultas devido à ausência do registro $\mathrm{CBO}$ (Classificação Brasileira de Ocupações) dos profissionais cadastrados. Discutiram-se alternativas e que as pessoas seriam contatadas, tendo prazo para efetivar a inscrição no cadastro de profissional, estudante ou pesquisador. Foram solicitados ajustes no sistema, como a inclusão da aba "documentos" no cadastro profissional, com treinamento agendado com os responsáveis pelo preenchimento dessas informações.

A equipe técnica conseguiu o financiamento no fim de 2013 para reestruturar a rede interna. À medida que a implantação avançava, percebeu-se a necessidade de registros de pacientes com categorias diversas (prontuário, apoio ao diagnóstico - registro de exames eventuais sem acompanhamento no Instituto, recém-nascido, natimorto, pronto atendimento/triagem). Houve discussões sobre as novas categorias por associar cada registro a um prontuário físico, que demandaria mais espaço, para controle de movimentação e localização. Consolidou-se a rotina de internação e registro no Sistema de Regulação do SUS (SISREG), sendo realizado pelo Núcleo de Internação e Regulação (NIR). O pronto atendimento foi alvo de discussão do grupo o ano inteiro e o departamento de pesquisa clínica solicitou acesso aos pacientes cadastrados para seus estudos retrospectivos.

Em 2014, a equipe de gestão do projeto constatou que o sistema RES não fornecia relatórios para atender à demanda da pesquisa clínica. $\mathrm{O}$ ano começou com um longo período de não funcionamento da rede de alta velocidade, devido a obras civis que danificaram a fibra ótica, fato agravado pela ausência do link de contingência adequado. Nesse meio tempo, a empresa responsável pelo RES comunicou que o sistema recebeu a certificação da SBIS.

O módulo de desenvolvimento de dose unitária para a farmácia que ia ser desenvolvido com outro hospital federal foi descontinuado. Em fevereiro, foram autorizados aquisição de servidores, storage, backup e investimentos numa sala de informática mais segura.

O processo utilizado para internação pelo sistema exige um pré-cadastro de leitos, com identificação do leito vago. A identificação de leitos na internação da neonatologia disponíveis na casa foi um fator de tensão entre a enfermagem e a equipe de gestão do RES, pois o sistema exigia mudança nesse processo.

A rotina de atualização dos registros dos recém-nascidos internados com os dados da certidão de nascimento até 72 horas de vida começou a ser discutida. Registros de atendimento anteriormente considerados necessários - pronto atendimento, apoio diagnóstico e natimorto vão se consolidando como prontuário, conforme a discussão com o setor. 
A equipe da empresa iniciou o esboço de soluções do módulo de dose unitária e o controle de psicotrópicos; ambas, demandas específicas da farmácia do Instituto. A empresa sugeriu que o desenvolvimento dessas soluções fosse implantado no sistema da empresa para que não houvesse uma interface externa. A rede de alta velocidade se estabilizou no fim de março.

A migração dos prontuários nos ambulatórios para o $P F H$ foi debatida, mas não se estabeleceu por problemas de infraestrutura de armazenamento físico e pendências no registro das modalidades de pronto atendimento. Um dos maiores desafios mencionados para a implantação do $P F H$ foi a dificuldade com alguns profissionais. Estes queriam dispor de formulários próprios, com informações separadas e com campos específicos, sob a alegação de que tinham o olhar diferenciado do especialista. Foi esclarecido que informações transversais (p.ex. o histórico do paciente) devem ficar mesmo nas áreas comuns, pois a duplicação de entradas levaria à duplicação de informações e risco de mau preenchimento. Mais grave seria a perda de confiabilidade com a redundância de informação registrada em mais de um campo. Qualquer profissional da assistência autorizado estaria habilitado a visualizar, atualizar ou complementar as informações transversais.

A equipe de TIC do Instituto apontou a necessidade de desenvolvimento de várias interfaces com aplicativos que os setores necessitavam utilizar e comprovou que o sistema contratado não interoperava com a maioria. Muitos serviços possuíam sistemas, planilhas ou, mesmo, formulários em papel para auxiliar no registro das informações de acompanhamento ao paciente e desejavam tê-los replicados nas telas do sistema. Essas questões implicam conhecer o processo de trabalho do profissional, os dados, as informações registradas no sistema. O uso de uma máquina de crise (que tem como objetivo permitir o acesso à informação dos doentes ativos no sistema, sendo um repositório de relatórios, sempre que o sistema falha) foi discutido, e por questões financeiras a instituição assumiu o risco de iniciar o projeto nos ambulatórios sem a referida máquina.

As atas de 2014 finalizam, explicitando a implantação do módulo de agenda e de movimentação de prontuários em várias especialidades e setores. Em 2015, observa-se perda de informação sobre procedimentos na movimentação de prontuários. Os erros são atribuídos ao mau funcionamento da rede. Outras rotinas na assistên- cia são implantadas, como por exemplo, o agendamento com antecedência. $\mathrm{O}$ arquivo médico do Instituto foi o setor escolhido para centralizar procedimentos de registros de admissão e alta hospitalar no módulo de internação do sistema gerencial.

A documentação que inclui tutoriais e $e$-learning do sistema, solicitada pela equipe de implantação à empresa em diversas reuniões, não atendeu às demandas para execução de procedimentos operacionais padrão ( $\mathrm{POP}$ ) e instrutivos de trabalho. A infraestrutura de rede prescindia de adequações, que foram implantadas paulatinamente a partir da aquisição do software do RES em descompasso temporal com o projeto. Ao longo do mesmo, houve mudanças de gerência, o que trouxe dificuldades em questões que precisavam de rápida resposta, como, por exemplo, a permuta de leitos, a movimentação entre clínicas, bugs no agendamento, tamanho do campo de inserção de códigos de procedimentos etc. A demora no atendimento às demandas de suporte gerou grande insegurança a toda equipe com uso do software. O comportamento da empresa não ofereceu confiança a médio e a longo prazo, pois o conhecimento esteve centrado em poucos profissionais. As solicitações de ajustes acolhidas pela empresa levavam cerca de 60 dias, em média, para serem disponibilizadas. A geração de receituários e relatórios não respeitava a identidade visual da instituição, tendo sido solicitada a modificação dos mesmos.

Com a implantação do módulo de internação, passou-se a imprimir a etiqueta com os dados do paciente, o que foi um ganho indireto, visto que, anteriormente, a pulseira de identificação de paciente era manuscrita. Procedimentos normativos inerentes ao ambiente hospitalar não previstos no sistema foram surgindo e a equipe de implantação municiou a empresa, à medida que surgiam os problemas.

Uma vez apresentados os relatórios consolidados por solicitação do setor de vigilância hospital, foi apontada a necessidade de informações sociodemográficas a serem incorporadas. O time de implantação do Instituto solicitou acesso à base de dados do sistema RES para responder às solicitações dos profissionais de auditoria do SUS.

Foi constatado nas atas, desacordo na definição das necessidades de informação dos dois institutos nacionais assistenciais. Reunião com a presidência da instituição estabeleceu que seus dois institutos nacionais deveriam compartilhar a mesma ferramenta para registro eletrônico 
de seus pacientes, originando um conjunto de tensões e divergências entre as equipes dos dois institutos e do nível de gestão central, no que diz respeito à construção da infraestrutura de suporte ao sistema RES.

Embora os gestores dos setores estivessem envolvidos, o grupo sinalizou grande desconhecimento do projeto, sendo propostos a emissão de comunicados periódicos e a confecção de cartazes, quando necessário.

Dificuldades financeiras da matriz sediada em outro país se refletiram na não participação presencial da gerente do projeto da empresa nas reuniões, por estar estabelecida em sede localizada em outra unidade federada. A necessidade de recursos para implantação e planos de contingências em eventuais inoperâncias foi citada em reuniões. Houve dificuldade em se garantir recursos humanos para o suporte, infraestrutura necessária para uso do sistema RES e educação permanente na utilização do mesmo, de acordo com as atas.

\section{Discussão}

O histórico sistematiza as percepções, interpretações e intenções dos pesquisadores sobre o processo de implantação do sistema de prontuário eletrônico no IFF, na tentativa de elucidar o sentido e o significado que o processo teve para os diferentes atores. Em outras palavras, caminhar pelas múltiplas forças que compõem o processo.

Conforme indica Foucault ${ }^{18}$, os saberes se constituem a partir de práticas políticas e econômicas, tecidas nas redes de relações cotidianas. As questões produzidas nos encontros, podem se configurar como um meio de abordar a implantação do RES, favorecendo o olhar nos processos subjetivos.

Nessa perspectiva, longe de constituir-se como análise de uma realidade estabelecida, esta investigação se propõe a iluminar elementos, conexões, linhas traçadas na constituição do campo institucional.

O envolvimento de muitos atores, tanto responsáveis pela implantação como os que registram no sistema, torna o processo mais complexo e árduo. Há casos em que uma mesma função é atribuída a duas ou mais pessoas de setores diferentes, o que gera atrasos.

Quanto às falas e pensamentos dos pesquisadores, é possível observar duas questões principais. A primeira é o fato de que o gerenciamento das exigências do cotidiano fica submetido aos processos instituídos, que interfere, mas não impede a autonomia como exercício diário na prática profissional. A outra questão diz respeito ao envolvimento nas tarefas facilmente capturado pela produção de "urgências" que a rotina diária estabelece no serviço.

- Modo de pensar- De um lado, o sujeito, de outro o objeto: são necessários muitos treinamentos de pessoal e, principalmente, o entendimento, por parte de cada profissional que registra, do porquê desse sistema ser tão importante para o IFF. (P1) A infraestrutura de rede foi implantada em descompasso com o projeto. (P2) Além dos tópicos apresentados as principais questões levantadas foram inerentes à baixa adesão e interesse dos funcionários na apresentação do Sistema. Foram ainda sinalizadas como entraves o desconhecimento sobre o projeto, e necessidade de divulgação de comunicado mensal, além de cartazes acerca do desenvolvimento do projeto de implantação. (P3) Necessidade de repensar, reajustar e compartilhar os processos de trabalho com o uso do sistema. Dificuldade de mudança de cultura arraigada no conceito de prontuário físico que ocupa espaço físico definido e tem-se controle em quem o acessa. (P4)

- Modo de se apropriar da ferramenta: Alguns setores/profissionais resistiram ao novo sistema, muitas vezes, se recusando até mesmo a registrar o prontuário. (P1) GT de gestão da informação foi criado. (P2) Houve ainda sinalização de dificuldades de apoio da empresa para o apoio em alguns procedimentos, o que causa insegurança aos participantes quanto à execução das etapas seguintes. (P3) Como somos um hospital de pesquisa, algumas vezes nos deparamos com alguma insegurança por parte de alguns profissionais com as novas formas de registro e acesso. Apesar do esforço, o corpo institucional, por vezes, demonstra algum desconhecimento com andamento do projeto. $O$ que leva a acreditar que as pessoas, mesmo as diretamente envolvidas, algumas vezes não conseguem se envolver e priorizar a implantação do sistema como desejado e necessário, devido provavelmente, às suas tarefas rotineiras e às dificuldades de acesso e disponibilização aos recursos necessários. (P4)

É possível identificar questões em nível organizacional. A produção de sentido aparece várias vezes associada ao fortalecimento da implicação dos profissionais, a autoria no processo de trabalho como possibilidade de criação de novos sentidos; a dicotomia entre processo e instrumento de trabalho; e o fato de que "restaurar o sistema" não se aplica somente à substituição de "papéis". Além disso, a abordagem coletiva dos atos permite a recriação de fluxos; e o automatismo das 
atividades pode ser quebrado pelo encontro das desestabilizações provocadas pelo grupo de trabalho de implantação do RES.

No processamento das informações, podemos destacar a importância da construção de ferramentas/espaços que possam suportar a constante tensão das práticas cotidianas no enfrentamento das problemáticas inerentes ao processo de implantação.

O diálogo das disciplinas da saúde se reflete na estrutura do RES. A constituição de um corpo a ser cuidado dentro e por meio do registro médico é um lugar de ativa contestação.

O RES legitima o desenho institucional, conta a história do trabalho que o corpo do indivíduo demanda da equipe. O RES organiza o trabalho, além de mapear a geografia do hospital. Uma geografia em que o cuidar se separa do curar. De acordo com as observações empíricas de Berg e Bowker, ele reproduz a hierarquia das seções do hospital, onde o médico está no topo e tem acesso ilimitado a todo sistema. Nenhum outro grupo pode sobrescrever as notas de acompanhamento e progresso do paciente, confirmando a soberania da clínica. A hierarquia das disciplinas está bem viva nos gráficos criados pelo RES ${ }^{10}$. Nesse caso, o diálogo estabelecido entre os setores do IFF e o grupo de trabalho para o estabelecimento de campos transversais nos formulários trouxe avanços importantes, que necessitam ser sempre pensados multidisciplinarmente e aperfeiçoados.

A ferramenta SWOT se mostrou eficiente para avaliar e descrever intervenções em saúde inovadoras e incipientes ${ }^{19,20}$, enfoques organizacionais amplos como a implantação do RES em sistemas de saúde nacionais ${ }^{21,22}$. No caso espanhol, a interoperabilidade entre diferentes estabelecimentos de saúde é apontada como uma questão central ${ }^{23}$. Em investigação sobre o surgimento da telessaúde no Brasil, aponta-se como questões que os sistemas computacionais em rede, que estruturam o sistema de saúde, devem trazer inovação, inclusão digital e interoperabilidade 9 . O consenso obtido pela análise problematiza a questão da interoperabilidade do RES entre diferentes organizações no sistema de saúde brasileiro na categoria ameaça.

Interoperabilidade de organizações envolve alinhamentos políticos e éticos importantes. Existem várias interoperabilidades: a local (nos hospitais e consultórios), a vertical (hospitais secundários, terciários e clínicas) e horizontal (hospitais, clínicas, conselhos de saúde e comunidade em geral), por exemplo. Muito do trabalho relacionado à interoperabilidade tem caráter puramente técnico, aparentando estar destituído de questões políticas e organizacionais.

A narrativa legal do registro médico é uma preocupação da autoridade hospitalar. Deve ser uma história bem contada de modo a não mostrar possíveis negligências. O RES, que constrói o corpo do paciente, serve como uma infraestrutura para uma série de organizações. Ele é feito de maneira que possa ser lido em conjunto com outros registros que essas organizações produzem.

A ênfase na interoperabilidade do RES como alicerce ferramental da clínica envolve uma série de alinhamentos organizacionais de grande importância ética e política. Porém, esses alinhamentos são colocados como questões puramente técnicas.

A integração do RES envolve relações com provedores de saúde, autoridades de saúde pública, a OMS (que mantém a Classificação Internacional de Doenças) e os conselhos profissionais, entre outros.

Berg e Bowker apresentam o caso dos Estados Unidos, em que há uma série de comitês envolvidos na padronização da informática médica, como a Health Level Seven (HL7) e a International Standard Organization (ISO) ${ }^{10}$. Cada proposta de interconexão é produto do esforço contínuo para manter e estabilizar uma infraestrutura de troca. Eles descrevem o caso de uma pesquisadora, que comprovou como a padronização Open System Interconnection (OSI) é resultado frágil de uma série de negociações entre a indústria da computação, reguladores governamentais e grupos de pressão da opinião pública, entre outros, para reter um núcleo proprietário de um sistema fechado ${ }^{10}$. A pesquisa dela documentou o esforço titânico entre os interesses corporativos e públicos, os quais estão inscritos no código OSI. Isso é típico de discussões, envolvendo questões técnicas de infraestrutura: quanto mais fundo se investiga, mais se aproxima das preocupações políticas e organizacionais ${ }^{24,25}$. Há uma necessidade da rede se organizar, para lidar com a tendência da manutenção de patentes e a resistência pelos ajustes necessários à padronização no campo das TICs aplicadas à saúde.

Uma das respostas aos problemas identificados é a interoperabilidade. No caso brasileiro, observando os cenários dos hospitais com serviços secundários e terciários do SUS, é possível identificar pelo menos três grandes sistemas hospitalares: o E-SUS Hospitalar em processo de implantação nos hospitais federais por intermédio do Ministério da Saúde; o Aplicativo de Gestão para Hospitais Universitários (AGHU), desenvolvido 


\section{Considerações finais}

Devido à estruturação do sistema $P F H$, o grupo de trabalho do RES identificou problemas como, por exemplo, o fato de os preceptores não terem seus registros associados aos atendimentos dos residentes no sistema. Isso poderia gerar indicadores no processo de ensino-aprendizagem e modificar a visão da produção, pois o sistema deve se aproximar ao máximo da realidade dos processos de trabalho.

A associação do prontuário físico com o digital exige uma mudança de cultura, especialmente, para os profissionais do arquivo médico, pois estes estão concentrados no controle, armazenamento e na localização concreta do prontuário de papel.

Há necessidade dos setores ajustarem seus processos existentes - muitas vezes, específicos para cada setor - em direção à uniformização para uso por um único sistema, que, por ser comercial, não possibilita customização integral das expectativas.

O RES materializa o ente legal do "cidadão no Estado". É necessário ser registrado para ter a atenção médica. Dessa ótica, o Registro é um ato de cidadania. Nesse sentido, há três principais aspectos legais constituintes do RES: a necessidade de o paciente ter acesso aos princípios do SUS: serviços (universalidade); o provimento da corre-

ta assistência (qualidade); e assistência de acordo com as especificidades do paciente (equidade).

Paralelo ao trabalho médico, essa história legal é produzida de acordo com os interesses das seguradoras, sendo, portanto, alvo de uma barganha preciosa para a indústria de informática e telecomunicações. O RES legitima tanto as ações como o gasto em saúde. O resultado de um registro legal (a moral da história) é a meta-afirmação de que o sistema médico é totalmente penetrado e sobrescrito pelo sistema legal, em que médicos fizeram tudo que poderia se esperar para aplacar a doença ou agravo, e que essas afirmações são justas. O RES registra a legalidade dos atos médicos.

Berg e Bowker sinalizam em suas observações que o núcleo de decisão do RES é do médico e o papel da enfermagem é o provimento de dados primários e a execução dos planos do médico. Embora enfermeiros passem mais tempo com os pacientes, a presença no RES é limitada ${ }^{10}$. Nessa história, os médicos são heróis e os pacientes objetos. O médico torna-se chefe das operações da ciência no corpo. O RES incorpora uma avaliação diferente, em que se opta por um tipo de contagem do tempo, o grau de importância da informação e destaca-se o trabalho que merece ser mencionado e visível ${ }^{26-28}$. Um olhar atento para o caso relatado mostra que a aparente morosidade nas decisões com as atividades do grupo de trabalho para implantação do RES e o diálogo com os setores evidenciam a participação das disciplinas e da comunidade hospitalar no cuidado.

Por fim, vale enfatizar que o RES se torna documento fundamental no controle de qualidade e na acreditação hospitalar. Além da informática médica, torna-se questão de saúde coletiva e de luta cotidiana histórica estar vigilante em relação aos diversos atores envolvidos na construção e reconstrução constante do corpo dos cidadãos nesses registros de saúde.

\section{Colaboradores}

AB Silva, ACCM Guedes, SRF Síndico, ETRC Vieira e IG Andrade Filha participaram ativamente nas diversas fases de preparação do manuscrito, sendo que todos participaram da concepção. ACCM Guedes, ETRC Vieira, SRF Síndico e IG Andrade Filha ficaram à frente da análise de dados e AB Silva e ACCM Guedes protagonizaram a elaboração de sua versão final, aprovada por todos. 


\section{Agradecimentos}

Dedicamos a Rui Baraúna de Rezende (homenagem póstuma), profissional do GT que muito contribuiu para a informatização da Fiocruz e a Fábio Bastos Russomano, coordenador do GT, que nos facilitou o acesso à documentação, prestando esclarecimentos ao longo da análise.

\section{Referências}

1. Topol EJ, Schork NJ, Smith JM. Digital medicine and the Scripps Translational Science Institute. Clin Transl Sci 2011; 4(1):8-9.

2. Lucena CDRX. Análise descritiva quanto às internações eletivas de 2012 e quanto à utilização do Cartão Nacional de Saúde (CNS) na Autorização de Internação Hospitalar (AIH) como estratégia para qualificação da informação em saúde. 2016. [citado 2015 Jul 10]. Disponível em: http://repositorio.unb.br/handle/10482/19736

3. Silva AB, Carneiro ACMG, Síndico SRF. Regras do governo brasileiro sobre serviços de telessaúde: revisão integrativa. Planejamento e Políticas públicas [Internet]. 2015. [citado 2015 Jul 10]. Disponível em: http://www. ipea.gov.br/ppp/index.php/PPP/article/view/440.

4. Minayo MCS. Os 20 anos do SUS e os avanços na vigilância e na proteção à saúde. Epidemiologia e Serviços de Saúde [periódico na Internet]. 2008. dez. [citado 2011 Maio 16]; 17(4):245-246. Disponível em: http:// scielo.iec.pa.gov.br/scielo.php?script=sci_arttext\&pi$\mathrm{d}=$ S1679-49742008000400001\&lng=pt.

5. Silva AB, Moraes IHS. O caso da Rede Universitária de Telemedicina: análise da entrada da telessaúde na agenda política brasileira. Physis 2012; 22(3):1211-1235.

6. Artmann E, Rivera FJ. A démarche stratégique (gestão estratégica hospitalar):um instrumento de coordenação da prática hospitalar baseado nos custos de oportunidade e na solidariedade. Cien Saude Colet 2003; 8(2):479-499.

7. Terry NP, Francis LP. Ensuring the privacy and confidentiality of electronic health records. 2007. [citado 2012 Out 6]. Disponível em: http://illinoislawreview.org/ wp-content/ilrcontent/articles/2007/2/Terry.pdf

8. Bireme. Biblioteca Virtual em Saúde. DeCS - Descritores em Ciências da Saúde. Pesquisa do termo prontuário. 2016. [acessado 2011 Dez 11]. Disponível em: http:// pesquisa.bvsalud.org/portal/decs-locator/?lang=pt\&tree_id=E05.318.308.940.968\&term=prontuario

9. Silva $\mathrm{AB}$. Telessaúde no Brasil - conceitos e aplicações. Rio de Janeiro: Editora DOC; 2014.

10. Berg M, Bowker G. The multiple bodies of the medical record: Toward a Sociology of an Artifact. Sociological Quarterly 1997; 38(3):513-537.

11. Moraes IHS. Política, tecnologia e informação em saúde: a utopia da emancipação. Salvador: Casa da Qualidade Editora; 2002.

12. Vasconcellos MM, Gribel EB, Moraes IHS. Registros em saúde: avaliação da qualidade do prontuário do paciente na atenção básica. Cad Saude Publica 2008; 24(1):173-182.

13. Silva ASL. Cartão Nacional de Saúde e o prontuário eletrônico do paciente no Brasil: Uma visão do estado atual. Resende: Associação Educacional Dom Bosco; 2007.
14. Silva FG, Tavares-Neto J. Avaliação dos prontuários médicos de hospitais de ensino do Brasil. Revista Brasileira de Educação Médica 2007; 31(2):113-126.

15. Farias JS, Tomas AG, Vargas ER, Albuquerque PHM. Adoção de prontuário eletrônico do paciente em hospitais universitários de Brasil e Espanha. A percepção de profissionais de saúde. Revista de Administração Pública 2011; 45(5):1303-1326.

16. Pahl N, Ritcher A. SWOT analysis: Idea, methodology, and a practical approach. Norderstedt: Grin Verlag; 2009.

17. Bardin L. Análise de Conteúdo. Lisboa: Edições 70; 2008.

18. Foucault M. Microfísica do poder. 16a ed. Rio de Janeiro: Graal; 2001.

19. Rizzo AA, Kim GJ. A SWOT analysis of the field of virtual rehabilitation and therapy. Presence 2005; 14(2):119-146.

20. Kuo M-H, Kushniruk A, Borycki E. Can cloud computing benefit health services? A SWOT analysis. Stud Health Technol Inform 2011; 169:379-383.

21. Noraziani K, Nurul'Ain A, Azhim MZ, Ekhab S, Drak B, Sharifa Ezat WP, Akma ASN. An overview of electronic medical record implementation in healthcare system: Lesson to learn. World Applied Sciences Journal 2013; 25(2):323-332.

22. Pereira R, Salazar M, Abelha A, Machado J. SWOT analysis of a Portuguese Electronic Health Record. IFIP Advances in Information and Communication Technology 2013; 399:169-177.

23. de la Torre I, Gonzalez S, Lopez-Coronado M. Analysis of the EHR systems in Spanish Primary Public Health System: the lack of interoperability. J Med Syst 2012; 36(5):3273-3281.

24. Tatnall A. Social Influences on Information and Communication Technology Innovations. Hershey: Information Science Reference; 2012.

25. Carlson WB. Innovation as a social process: Elihu Thomson and the 'rise of General Electric. Cambridge: Cambridge University Press; 2003.

26. Egger E, Wagner I. Negotiating temporal orders. Computer Supported Cooperative Work (CSCW) 1992; 1(4):255-275.

27. Frankenberg R. "Your time or mine?" An anthropological view of the tragic temporal contradictions of biomedical practice. Int J Health Serv 1988; 18(1):11-34.

28. Star SL. Ecologies of Knowledge: Work and Politics in Science and Technology. New York: State University of New York Press; 1995.

Artigo apresentado em 10/08/2016

Aprovado em 01/06/2017

Versão final apresentada em 03/06/2017 